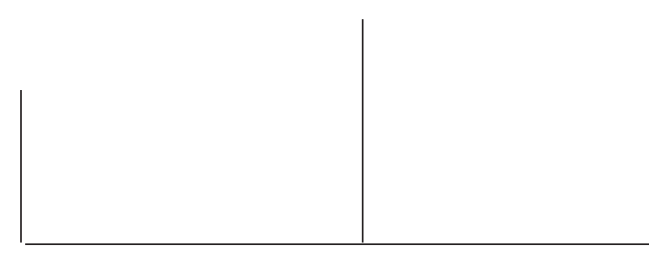

Rev. Latinoam. Psicopat. Fund., V, 1, 152-163

\title{
Las metáforas de Terpsícore
}

\author{
Nafia Marianne Laurence Bahena Yaghen-Vial
}

Freud inaugura el estudio del psicoanálisis hablando de la relación mente-cuerpo con el concepto de pulsión que marca un puente entre el cuerpo y la psique. Por otra parte, Lacan aportara el concepto de apuntalamiento para fundamentar el surgimiento y separación del orden del deseo a partir del orden de la necesidad.

Analizar el vínculo danza-psicoanálisis es muy interesante abordarlo porque es una manera de preguntarse, desde otra perspectiva, sobre el rol que tiene el cuerpo para la teoría psicoanalítica.

Por ello, desde el psicoanálisis se podría decir que la danza pone en esencia el cuerpo del deseo aunque su objeto de amor permamezca velado. La danza es un arte de la representación, es un producto del mundo simbólico que por medio del cuerpo traza y evoca (a modo de una metáfora) el mapa del alma humana.

Palabras llave: Danza, metáfora, cuerpo, deseo 
El sujeto hablante que se considera ilusoriamente dueño de su discurso dice siempre más de lo que habla y habla sin saber lo que dice.

Daniel Gerber

El inconsciente se manifiesta por medio de metáforas y eso es lo que el sueño descubre.

Octave Mannoni

Dado que el ser humano se funda a partir del lenguaje y por ello, el discurso es una buena opción para efectuar la exploración de la subjetividad, una gran contribución del psicoanálisis es el hecho de que el sujeto no es dueño de su discurso ya que la significación de éste no radica en el sentido literal de las palabras sino en la manera en que aparece la relación inconsciente-palabra y en consecuencia en la manera en que aparece en el lenguaje articulado. Al respecto, Margarita Baz (1996, p. 212) en Metáforas del cuerpo. Un estudio sobre la mujer y la danza escribe: "El discurso es trama porque es estructura, es tejido, es sostén: las dimensiones elegidas son, entonces, hipótesis sobre el contenido latente del texto. Y aquí es evidente la toma de posición respecto a la forma de concebir el discurso".

El discurso, a partir de la teoría lacaniana, es una producción simbólica construida por dos lógicas diversas. La primera es la del sujeto del enunciado que, en francés, es identificado con el pronombre personal "je" (yo), que habla desde una identidad imaginaria, y que relata su discurso a modo de una novela, desde una aparente posición de control que busca garantizar cierta coherencia y racionalidad. A esta función del yo se le reconoce como una estructura de desconocimiento porque el sujeto cree saber y no sabe, o sabe poco de su deseo que es inconsciente y sus vicisitudes. En lo que se refiere a la otra lógica es la del inconsciente que se revela 


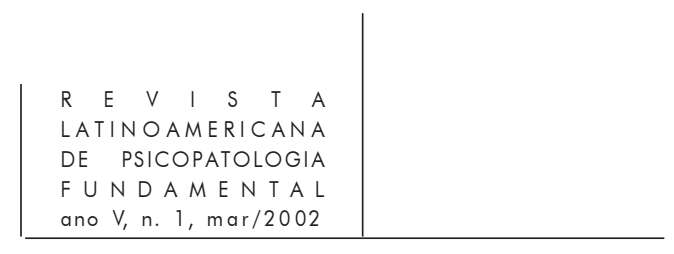

por su "hablar metafórico" el cual va formando diversos temas que son, en realidad, los nudos de la estructura subjetiva con los cuales el sujeto se enfrenta y va formando su vida.

Dicho de otra manera, la organización libidinal de cada sujeto aparece modelada por una fantasmática singular que insiste, se revela y se expresa de distintas maneras. Una de ellas puede ser por medio del movimiento de la danza, como sucedió con el bailarín ruso Vaslav Nijinsky (1889-1950), por ser una metáfora privilegiada para simbolizar y expresar el movimiento por medio del cuerpo. Sin embargo, otro reto al que se enfrenta la danza es justamente el de poner en movimiento la fantasmática de la imagen corporal que está ligada a los enigmas fundamentales de la constitución del sujeto, es decir, la existencia, la sexualidad y la muerte.

Despertar el cuerpo para que hable sin la mediación de la palabra - tarea de la bailarina - es animarse a emprender un viaje de sobresaltos y riesgos donde se van a reeditar procesos básicos que fincaron la constitución misma del sujeto. Uno de esos procesos fundamentales, que resulta clave para analizar el vínculo con el cuerpo, tiene que ver con el narcisismo y su mundo de imágenes, identificaciones e idealizaciones, el cual determina nudos específicos en la estructura subjetiva, como son: la tensión omnipotencia, la castración y la problemática identidad/apariencia ambos elementos entreverados con un proceso del que se habla mucho pero se comprende poco, y que es la valorización de sí mismo. Esta problemática aparece en forma relevante en el material de campo con el que trabajamos. (Ibid., p. 216)

El arte en general encierra un deseo de trascendencia de los límites humanos y en el caso de la danza, éste tiene que ver con la ilusión de trascender aquello que caracteriza al cuerpo humano, es decir, lo precario, lo efímero, lo temporal y lo limitado. De este modo, la danza permite recrear en el escenario la ilusión por un cuerpo luminoso y mítico por medio de la fantasía y la imaginación. En este sentido podemos decir que la danza compromete necesariamente el mundo fantasmático vinculado a la forma humana, la cual resulta "omnipresente” en el imaginario tanto individual como colectivo. Por ello, el cuerpo se le puede definir como un lugar de inscripción de la lógica de los signos y significados que definen el mundo humano ya que es una construcción significante, un referente primordial del "yo" que se encuentra inmerso en un mundo imaginario donde los mitos individuales y sociales se alimentan y sostienen. Al mismo tiempo que es un referente constante de experiencias intensas a nivel sensorial, motriz, erótico, entre otras.

En este sentido, la danza constituye un sistema de organización de la experiencia vivida, expresada por medio de una técnica representativa. La danza no reproduce una realidad ya dada, sino que inventa una visión del espacio y del tiempo, de la forma y de un significado que no es ficticio porque se basa en vivencias concretas. Ahora bien, para poder expresar esta serie de vivencias, la danza se vale de signos comunicativos que deben compartir un código para establecer una correspondencia 


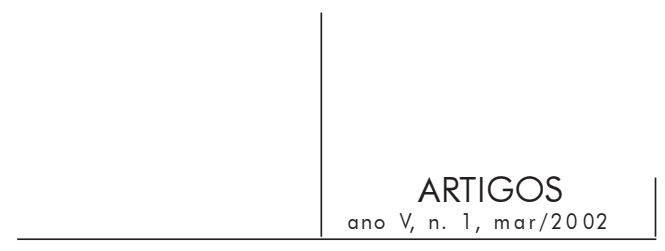

entre significante y significado que susciten interés, admiración y puedan despertar distintas emociones que incluso puedan llevar al espectador a experimentar y a evocar sus propias experiencias vividas y sus propios recuerdos.

La danza es, más que un lenguaje, una escritura figurativa que posee una gramática y una lógica propias independientes a las de la conciencia ligadas al logos y a la fonética. Por lo que el desciframiento de ciertos elementos no está destinado a ser interpretado sino que está para determinar el significado de algún otro elemento a partir de un contexto. Ahora bien, si pensamos que la danza es una escritura anterior al lenguaje podemos decir que ésta posee una lógica que pone en acción los procesos primarios - condensación, simbolización y desplazamiento - que rigen el sistema inconsciente.

Estos procesos figurativos no hacen referencia a una presencia y a un significado que se encuentran en lo exterior, sino a conflictos de fuerzas que se hallan estructurados por el texto de la obra de arte. Esto los capacita para transformar el sentido de las relaciones establecidas donde la representación y el afecto no son indisociables porque en ellas convergen las fantasías y el deseo del autor para dar nacimiento a una obra perfectamente original. Por ello, existen formas presentativas capaces de conferir una estructura objetiva a las emociones, como son la música y la danza porque expresan lo inefable de los sentimientos con más precisión que el lenguaje y por ello exigen una semántica adecuada. Para Langer, el arte realiza una abstracción porque crea símbolos, formas significativas.

La forma discursiva del arte es orgánica, y su cometido es representar la experiencia vital o la estructura dinámica de las emociones. La abstracción es inmediata y es la de un conjunto indivisible, cuyas partes sólo tienen sentido dentro del todo. En consecuencia, el símbolo artístico es creado para su contemplación y comprensión, no para instalarse en él como en un refugio separado de la vida real. Para ejemplificar este razonamiento, Langer, con relación a la danza, escribe:

La danza es una imagen dinámica de fuerzas interactivas, de un despliegue virtual de potencias en acción. Lo que nos presenta la danza son los centros aparentes de poder y sus emanaciones, sus conflictos y resoluciones, su elevación y su caída, su vida rítmica. Estos elementos creados en la apariencia no son los físicamente dados, sino los artísticamente figurados, no el síntoma de los sentimientos del danzante, sino una expresión de conocimiento que tiene el coreógrafo de los sentimientos humanos. La danza expresa a su manera estos sentimientos, los ritmos y conexiones, las crisis y rupturas, la complejidad y riqueza de lo que suele llamar la vida interior, la corriente de experiencia directa. Es una manifestación externa de una naturaleza interior, una presentación objetiva de realidad subjetiva; y simboliza estos hechos de la vida íntima reproduciendo el mismo orden de sus relaciones y elementos. Por eso puede ser una objetivación de la subjetividad. (Kogan, 1965, p. 59) 


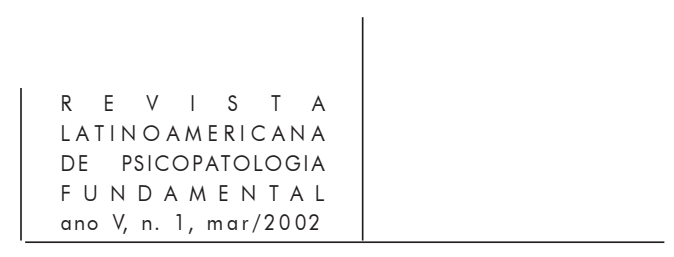

Esto se debe quizás a que el bailarín inventa y construye un objeto capaz de cambiar nuestro sentir y en consecuencia nos conduce a otra dimensión donde el espectador podrá experimentar aquello que se llama goce estético.

"La obra de arte no se limita, por tanto, a presentar un símbolo a nuestra intelección, sino que con su forma y su color, su sonoridad y su ritmo, sus sentimientos evocados o ideas sugeridas, nos hace revivir una experiencia estética del artista dentro de una unidad de sentido que es su estructura" (Ibid., p. 70).

Para Gilson (Ibid.) la danza es una creación material de algo que sin ésta no podría existir. El bailarín no se limita a expresar un sentido a través del movimiento, no es una imagen virtual lo que produce, sino que trae a la existencia algo sustancial: la realidad misma de su creación. Mientras que Kandinsky (1994, p. 92) en Sobre lo espiritual en el arte con relación a la danza escribe:

(Es) el único medio que puede expresar toda la significación y el sentido interno del movimiento en el espacio y el tiempo. Parece que el origen de la danza es puramente sexual. Hoy todavía perdura este elemento primitivo en las danzas populares. La posterior necesidad de utilizar la danza en el servicio religioso (medio para la inspiración) no sobrepasa el nivel de la utilización práctica del movimiento. Paulatinamente el uso práctico va adquiriendo un matiz artístico, que va perdiendo progresivamente claridad, resultando hoy comprensible para muy pocos. El lenguaje del ballet, además excesivamente ingenuo para los tiempos que se avecinan: sólo tiene capacidad para expresar sentimientos materiales (amor, miedo...) y debe ser sustituido por otro capaz de estimular vibraciones anímicas más sutiles. Este es el motivo de que los actuales reformadores de la danza hayan vuelto los ojos a formas anteriores en busca de ayuda. Así es como Isadora Duncan ha establecido entre la danza griega y la danza futura.

La danza contemporánea o moderna es un estilo creado para expresar los sentimientos. Sus orígenes datan de finales del siglo XIX cuando algunos bailarines sintieron demasiadas restricciones en el ballet para expresarse. Isadora Duncan (1877-1927) es una de las figuras que más destaca porque supo resucitar, utilizar y fusionar los ideales del antiguo arte griego para inspirar formas más naturales de danza donde el cuerpo humano sirve como un instrumento de expresión emocional por lo que sentir los movimientos es esencial. Isadora Duncan creyó en la belleza perfecta. De Atenas hizo su ideal para constituir las bases para la renovación de la danza, por ello resulta prácticamente imposible referirse a la danza moderna sin tomar en cuenta los lazos estrechos que la unen con esta cultura, sede espiritual de sus coreografías e improvisaciones.

En efecto, Isadora Duncan fue una revolucionaria de la danza al haber ampliando las fronteras creativas para que muchos artistas pudieran expresarse mediante el lenguaje de la danza escénica moderna. Isadora Duncan creó coreografías cuyo objetivo no eran para divertir ni entretener sino para mostrar al espectador la 


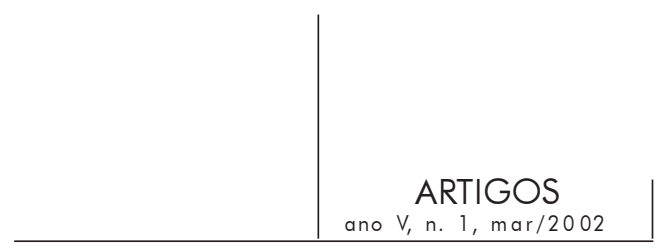

complejidad que se estaba viviendo en su época. Sus danzas estaban llenas de pasión y protesta y así enfrentaba al gusto clásico que se basaba en motivos completamente alejados de la realidad. En este sentido, podemos decir que Isadora Duncan transgredió los cánones de la danza clásica porque mientras que ésta siempre trabaja en las formas graciosas y bellas siguiendo una historia lineal, la danza moderna rompe completamente con este esquema.

En este sentido, el rescate que hizo Isadora Duncan de la danza es muy significativo porque no sólo le devolvió su sentido original, es decir, comunicar el lado claro y oscuro de la vida basándose en ideas, sensaciones y sentimientos sino que al congregar poesía y música en improvisaciones escénicas la regresó su posición privilegiada, a saber, la de ser una metáfora. Si algo son la danza y la poesía es que son justamente metáforas. Por esta razón, este artículo se titula Las Metáforas de Terpsícore. ${ }^{1}$

La danza es un lenguaje vivo que habla del hombre porque es un mensaje artístico que va más allá de la realidad con el propósito de hablar, por decirlo de algún otro modo, en un nivel más alto a partir de imágenes, alegorías sobre las emociones más íntimas del hombre y de su necesidad de expresarse. En efecto, la danza para el artista constituye un medio de creación a partir del cual puede inventar y crear. Es como si se tratara de una poesía en la que sus pensamientos se convierten en imágenes. Ahora bien, la pregunta que nos podríamos plantear consiste en saber cuál es la causa que hace que la danza y su expresión (aún si no se dejan encerrar por la palabra o la escritura porque las rebasa) estén estrechamente ligadas al hombre y a su capacidad de expresión a través del cuerpo. La explicación se puede basar en el hecho de que el hombre es a la vez en sí mismo emisor y su cuerpo es el medio, el instrumento y el material significante a causa de su movimiento natural que constituye el material de la danza a causa de su movimiento natural.

La danza como lenguaje es en sus formas múltiple y es susceptible a ser eternamente modificada. Cabe destacar que el movimiento del cuerpo en sí, no puede ser identificado como danza aún si es la base elemental e irrefutable sin la cual no podría existir. En el momento en que el hombre bailando libera el deseo de hacer

1. Recordemos que Terpsícore es la que deleita en la danza por lo tanto es la Musa de la danza así como de la poesía ligera y era representada con una lira. Recordemos que las Musas son la representación griega de los poderes creadores de la mente. Según Hesíodo (siglo VIII a.C.) son nueve hermosas diosas engendradas por Zeus y Mnemósine que habitaban en el monte Parnaso protegidas por Apolo, el dios protector de todas las artes. Las Musas son las cantoras divinas que con sus coros e himnos deleitan a los dioses en el Olimpo. Por otra parte, las musas podían descender durante la noche a la tierra, actuando como mediadoras entre lo divino y los mortales convirtiéndose en fuente de inspiración de toda clase de arte. 


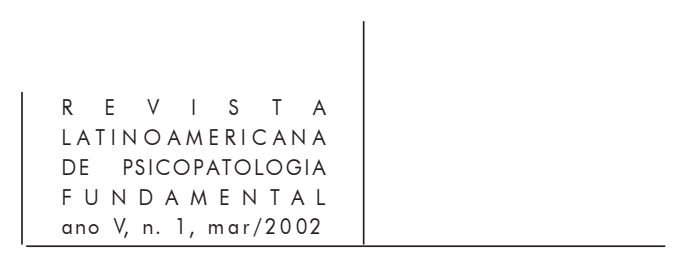

visible aquellas imágenes que todavía permanecen invisibles, es gracias al movimiento del cuerpo que estas imágenes manifiestan su primera forma de expresión.

Es importante señalar que el movimiento natural otorga un sentido y una significación al lenguaje del gesto estéticamente concebido y estructurado porque la danza no puede ser comprensible si no respeta y mantiene su responsabilidad y el compromiso de transmitir de manera clara el sentido con relación al lenguaje gestual natural del hombre. Más allá de la interpretación personal a cargo del bailarín, existe siempre el significado universal de la obra, es decir, que el bailarín por medio de su interpretación puede cambiar arbitrariamente el mensaje.

Al igual que la música, la danza es también un arte del tiempo en la medida en la que se hace referencia a los pasajes rítmicos medidos y controlados en el tiempo. Sin embargo, es preciso poner énfasis en que el ritmo de la danza no se determina únicamente según los criterios del tiempo aún si el conteo de las medidas para los bailarines es capital; así como para el trabajo coreográfico durante el proceso de creación y posteriormente en los ensayos. Por lo tanto el tiempo es de suma importancia porque por medio de él se asocia la estructura de estos dos lenguajes que se compenetran, la danza y la música, con el fin de ajustarlos el uno con relación al otro en un curso temporal, y de unirlos en una comprensión armoniosa. En efecto, el tiempo marca las transiciones de un tema a otro, precisa los acentos, los momentos de respiración y de suspensión. Mientras que el músico cuenta según una línea musical, el bailarín hace lo mismo pero según el ritmo del movimiento de su cuerpo.

La música ha sido el arte que ha utilizado sus propios medios para expresar la vida interior del artista y crear una vida propia, y no para representar o reproducir fenómenos naturales. El artista pretende expresar su mundo interior y en esto la danza puede ser un excelente medio de comunicación.

La danza es un arte de la representación. En su realidad teatral, la danza depende de su intérprete legítimo, es decir, el bailarín que a su vez sólo puede expresarse durante los breves instantes de la representación, la realización artística de la danza es limitada en el tiempo y está ligada al instante. La obra coreográfica se convierte inmediatamente en una imagen en la memoria, que sólo puede ser resucitada y preservada desde un cierto punto; porque tenderá a desaparecer según su nivel de excelencia y la calidad de su interpretación.

A pesar del carácter efímero, fugaz, propio de la danza; ésta quiere ser y debe ser vista porque es de esta manera que se convierte en una fiesta para los ojos al mismo tiempo que es una experiencia conmovedora, encantadora y seductora. Generalmente, esto se logra cuando coincide en un ser el sentido de las estructuras musicales, la técnica danzística perfecta y una presencia escénica potente que le permitan forjar una expresión, un estilo, y de fijar su huella artística personal como sucedió con Vaslav Nijinsky que supo darle un nuevo giro a la danza clásica para darle nacimiento a la danza moderna. 


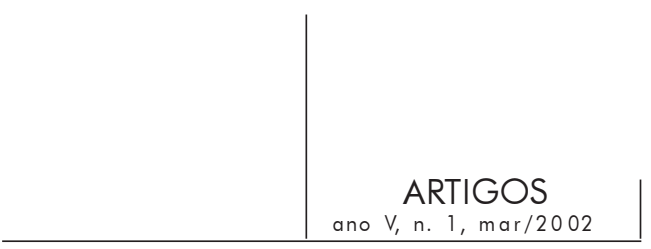

El movimiento y la alteridad en la danza

Nací a la orilla del mar, mi primera idea del movimiento y de la danza me han venido seguramente del ritmo de las olas.

Isadora Duncan

La relación cuerpo-psique da origen al nacimiento del psicoanálisis porque marca una ruptura tajante sobre el estudio del cuerpo que hasta ese entonces sólo había permanecido en el ámbito de lo biológico y por lo tanto sin relación ninguna con la mente. Freud inaugura el estudio del psicoanálisis hablando de la relación mente-cuerpo con el concepto de pulsión que marca un puente entre el cuerpo y la mente. Por otra parte, otra idea importante introducida por Lacan es la del apuntalamiento para fundamentar el surgimiento y separación del orden del deseo a partir del orden de la necesidad.

Recordemos que en psicoanálisis es muy importante marcar la diferencia entre deseo y necesidad porque esta última surge del reconocimiento de que la existencia en tanto cuerpo se vale de ciertas funciones para la conservación de la vida que son las necesidades instintivas que deben ser satisfechas como ocurre en los animales. A partir de las primeras experiencias placenteras, las pulsiones sexuales se vuelven autónomas porque aparecen como un suplemento de placer que no se reduce a la mera satisfacción de la necesidad de alimento sino que se asocia el objeto pecho por el cual se va sentir un deseo. Es muy importante señalar que el deseo, la fantasía y la pulsión además de ser fundantes de la realidad psíquica, son, para el psicoanálisis, inconscientes. Por lo tanto, querer analizar el vínculo danza-psicoanálisis es partir del cuestionamiento de qué significa el cuerpo para esta disciplina porque es a partir de él que el bailarín evoca fantasías inconscientes.

En el transcurso de la historia de la danza, ésta ha tenido diversas funciones sociales adoptando diversas formas y expresiones que resaltan aspectos significativos del desarrollo de las culturas. En su expresión primitiva fue considerada un conjuro mágico que se traducía en danzas de la lluvia, de la fertilidad, entre otras, al mismo tiempo que cobró un papel importante como ceremonial así como religioso (danzas sagradas). Sin embargo lo esencial es reconocer que la danza es la primera modalidad expresiva del ser humano acorde con el mundo en el que está inmerso. En efecto, la esencia de la danza es el movimiento que crea una plástica bajo el sustento del ritmo y la armonía, y cuyo instrumento es el cuerpo. Por lo tanto podemos decir que la danza es un producto del mundo simbólico que por medio del cuerpo traza y evoca el mapa del alma humana.

Por otra parte, la danza es la metáfora privilegiada del acto de poner en movimiento aquellos elementos que tienden a expresarse de manera rígida. La especifici- 


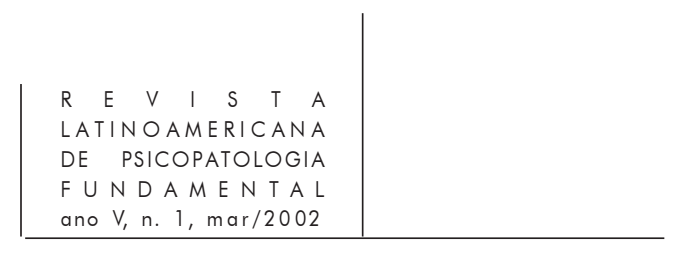

dad de la danza consiste en su acto de creación a partir de un cuerpo, que una vez activado en su dimensión erótica permite que se produzca una catarsis. En efecto por medio del movimiento, la danza tiene el deseo de trascender lo limitado del cuerpo. Al respecto Margarita Baz (1996, p. 127) cita a P. Schilder de la siguiente manera:

Por su parte, P. Shilder, en su estudio psicoanalítico y psicosociológico sobre el cuerpo humano, reconoció que, en general, el ser humano tiene la necesidad de un continuo jugar con el cuerpo y con su imagen, y habló del enorme placer derivado de franquear las limitaciones corporales. Esto es consecuencia de ese proceso que él describió como una imagen corporal en perpetua autoconstrucción. En ese contexto, consideró la danza como una forma privilegiada para disolver o debilitar la forma rígida del esquema del cuerpo, esta actividad decía, "acarrea una actitud psíquica determinada" en la medida en que produce un "aflojamiento y alteración de la imagen corporal". En otras palabras, según esa hipótesis, la danza flexibiliza y cambia, pero no nada más el cuerpo, sino la sensibilidad frente a uno mismo y el mundo; asimismo, mostraría sus efectos en la dinámica libidinal, es decir, en la configuración fantasmática de nuestro cuerpo diseñada por nuestros deseos inconscientes.

Al ser perecedero y limitado el cuerpo, el bailarín se vale de éste como su instrumento por medio del cual realiza un arte que como él se distingue también por ser efímero. Una vez que el bailarín ha concluido su ejecución, ésta se distingue por su carácter efímero porque es irrepetible, no es permanente. Por lo que cada ejecución puede ser considerada como una ofrenda que realiza y a la que se entrega constante y pasionalmente el bailarín para así satisfacer sus pulsiones.

Esto puede darse gracias a la puesta en escena porque coloca a la danza en una dimensión teatral que es capaz de producir a modo de una ilusión, por medio de la sublimación, la omnipotencia de los deseos. Por ello, la danza tiene una connotación mágica que incluso ha sido registrada en diferentes manuales de antropología como la más antigua forma de magia que creó el ser humano.

La danza en su evolución histórica se volvió espectáculo teatral y expresión artística instituida, pero no abandonó el gesto de la ofrenda: cuerpos que se ofrecen en un ritual que evoca las antiguas ceremonias sagradas. Dicen las bailarinas: "Hay un compromiso, un amor, la imaginación de uno se alimenta de sentimientos fantásticos". "Es una sensación misteriosa, cuando estás en función tu mente cambia, tu sensibilidad es diferente, incluso tu equilibrio". La escena es sagrada en la medida en que actúa en el imaginario colectivo del grupo de danza para darle el lugar del ideal. En ella el bailarín está desnudo: no hay más ensayos, correcciones, repeticiones, ahí realmente "es", en un momento efímero de entrega. (Ibid., p. 131)

Por ello, desde el psicoanálisis se podría decir que la danza pone en esencia el cuerpo del deseo aunque su objeto de amor permanezca velado ya que "la danza es 


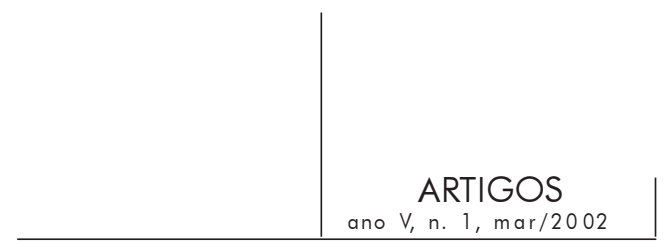

una palabra hermética, que no se sabe, como toda palabra de amor" (Ibid., p. 132) pero capaz de "producir un mundo mítico devotamente consagrado a perfeccionar el cuerpo para celebrar momentos oníricos de gran intensidad. El acto en la escena equivale a un conjuro: quizá el del cuerpo mortal confrontado con el cuerpo divino. Ciertamente hay un vínculo con lo "maravilloso" y una práctica de adoración" (Ibid., p. 132).

Sin embargo, otro carácter propio de la danza que es necesario resaltar consiste en ser una actividad creada para seducir debido a la gran carga erótica que despliega por medio del lenguaje corporal de los bailarines ya que "en la danza se adivina la condena de una promesa, el cuerpo del bailarín/bailarina es un surco, una seña legible, truncada de la unión sexual: fantasía retrospectiva, memoria o expectación, es siempre una promesa incumplida" (Ibid., p. 133). El cuerpo danzante es un poderoso ejemplo de cómo se produce un fenómeno cultural en el que varias fuerzas vitales se conjugan donde el bailarín es el medio por el cual se expresa un conjunto de deseos.

Al ser un arte plástica que está fundada en el cuerpo, la danza está en íntima relación con el imaginario, lo que a su vez nos remite a la problemática de la mirada. En efecto, el bailarín forzosamente se forma frente a un espejo que lo enfrenta diariamente con la imagen de su cuerpo que le revela cómo luce. Esta confrontación permanente a la que se expone el bailarín es de gran interés porque representa una manera de exigirle que cumpla con un modelo ideal del cuerpo (esto es el ideal imaginario).

En consecuencia, el bailarín es alguien que permanentemente se mira al mismo tiempo que mira a sus colegas (la compañía de danza) que son representantes de ese ideal. En este sentido, la danza está íntimamente ligada al narcisismo pues recordemos que la mirada dirigida hacia un otro es constitutiva para el sujeto humano. Por lo tanto, en el caso de la danza, la mirada del bailarín hacia un otro es constitutiva y es fuente de un placer que despierta una gran fascinación que hace que se quiera capturar esa magia del movimiento del otro.

Por otra parte, esta cuestión de la mirada no sólo se reduce en el ámbito institucional de la danza porque el bailarín está expuesto a una mirada anónima que lo legitima como bailarín, es decir, la del público que tras mirarlo y juzgarlo le otorga o no, su reconocimiento. Esta mirada colectiva que funge como una mediación, sitúa la vulnerabilidad del bailarín. Ahora bien, desde el psicoanálisis podríamos decir que el bailarín vive con profunda intensidad el hacerse mirada que se divide en tres momentos que son: mirarse, mirar y ser mirado. Por otra parte, es importante señalar que al ser el escenario un lugar que posibilita la realización imaginaria del deseo permite que se dé un levantamiento de la represión al mismo tiempo que se cede al goce.

Por ello, desde el psicoanálisis, se puede decir que el juego imaginario en el bailarín además de actualizarse constantemente, está muy patente debido a las grandes presiones institucionales que le imponen una sumisión a los ideales de un cuerpo 


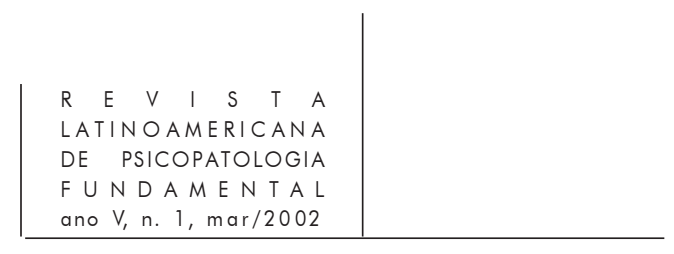

perfecto. En efecto, ese universo de miradas en el que vive el bailarín es el que propicia una metamorfosis del cuerpo que hace surgir la dinámica del yo y su doble, del yo y el otro, a modo de una alternancia entre la sensación de extrañeza y la alienación en la imagen, entre la posibilidad de "ser otro" o la verificación de la indistinción del sujeto con sus imágenes. Al respecto, Margarita Baz (Ibid., p. 1378) escribe: "El cuerpo danzante se ve atrapado en el ritual de las apariencias para constituirse en un vehículo de proyección colectiva, ritual mágico cuyo guión eje es la fantasmática inconsciente centrada en la imagen corporal".

Dada la peculiar relación que tiene el arte con la fantasía y la ilusión, en la danza se manifiesta a partir de las imágenes corporales al proponerse representar y ofrecer la metáfora de un cuerpo para el otro y ésto se debe gracias a la inscripción del sujeto en el registro de lo simbólico, es decir, el Otro que a su vez es la condición indispensable para que el sujeto pueda construirse objetos imaginarios de deseo. Uno de esos objetos, por medio de los cuáles el hombre puede expresar su debate entre sus pulsiones de vida y de muerte, es precisamente la danza porque por medio del lenguaje musical, corporal y plástico evoca de una manera mítica y simbólica la condición humana.

\section{Referencias}

Assoun, Paul-Laurent. Psychanalyse. Paris: PUF, 1997.

$\mathrm{BAz}$, Margarita. Metáforas del cuerpo. Un estudio sobre la mujer y la danza. México: Grupo editorial Porrúa. UAM Xochimilco y UNAM, 1996.

Duncan, Isadora. Mi vida. Buenos Aires: Losada, 1989.

Kandinsky, Vasili. Sobre lo espiritual en el arte. México: Cinar Editores, 1994.

Kogan, Jacob. El lenguaje del arte. Buenos Aires: Paidós, 1965.

LACAN, Jacques. El Seminario. Libro 2. El Yo en la teoría de Freud. Clase 22 ¿dónde está la palabra? ¿Dónde está el lenguaje? 15 de junio de 1955. En Cd rom: Los Seminarios del -1 al 27 de Jacques Lacan.

Laplanche, J. y Pontalis. J.-B. Diccionario de psicoanálisis. Colombia: Labor, 1994.

\section{Resumos}

Freud inaugura o estudo da psicanálise falando da relação mente/corpo com o conceito de pulsão que marca a ponte entre o corpo e a psique. Por outro lado, Lacan trouxe o conceito de reforço (apuntalamiento) para fundamentar o surgimento e a separação da ordem do desejo a partir da ordem da necessidade.

É muito interessante analisar o vínculo dança-psicanálise porque é uma maneira de se indagar, deste outra perspectiva, sobre a relação que o corpo tem para a teoria psicanalítica.

A partir da psicanálise poder-se-ia dizer que a dança coloca em essência o corpo 
do desejo, embora seu objeto de amor permaneça velado. A dança é uma arte da representação, um produto do mundo simbólico que, por meio do corpo, traça e evoca ( na forma de uma metáfora) o mapa da alma humana.

Palavras-chave: Dança, metáfora, corpo, desejo

Freud inaugure l'étude de la psychanalyse en abordant la relation de l'esprit et du corps avec le concept de pulsion qui établit un pont entre le corps et la psique. D'un autre côté, Lacan amènera le concept de "apuntalamiento" pour rendre compte de l'émergence et la distinction de l'ordre du désir par rapport à l'ordre du besoin.

Vouloir analyser le lien danse/psychanalyse est très important car c'est partir du questionnement de ce que signifie le corps pour cette discipline puisque c'est par l'intermédiaire de ce corps que le danseur évoque ses fantaisies inconscientes.

A partir de la psychanalyse on pourrait dire que la danse révèle l'essence du corp $d u$ désir alors que son objet d'amour demeure voilé. Lacan danse est un art de représentation, c'est un produit du monde symbolique qui par l'intermédiaire du corps représente et évoque (selon le mode de la métaphore) la carte de l'âme humaine.

Mots clés: Danse, métaphore, corp, désir

Freud began his study of psychoanalysis by referring to the relationship between mind and body, using the concept of the drive to serve as a bridge between the two. Lacan, in contrast, used the concept of "shoring" (apuntalamiento) to refer to the appearance and separation of the order of desire from the order of need.

An anaysis of the relationship between dance and psychoanalysis is an intriguing way to study the relationship between the body and psychoanalytic theory, from a unique perspective.

For this reason, based on psychoanalysis, it can be said that dancing places the body of desire in essence, even though its object of love remains concealed. Dancing is an art of representation, a product of the symbolic world which, through the body, invents and evokes the map of the human soul through metaphores.

Key words: Dance, metaphor, body, desire

Versão inicial recebida em julho de 2001

Aprovado para publicação em janeiro de 2002 